have now been able to establish that these sera completely inhibit the action of the homologous enzyme on the viscosity or the substrate and the liberation of reducing substances; there is no cross neutralization of this activity.

It is of considerable interest that, although these enzymes cause an immediate fall in the viscosity of the substrate, no reducing substances can be detected for some hours. With a preparation of the diffusing factor of $\mathrm{Cl}$. welchii, which causes a marked fall in viscosity in a few minutes, only a trace of $\mathrm{N}$-acetyl glucosamine can be detected after four hours and the maximum is not attained until after 18-24 hours incubation. At first it was thought that enzymes from different natural sources differed qualitatively as well as quantitatively in their capacity to liberate reducing substances; when, however, the concentration of enzymes from testis, $C l$. welchii and viper venom was adjusted so that the reaction times for the reduction of viscosity were comparable, it was found that the amount of enzyme necessary to liberate detectable reducing substances was approximately the same whatever the source. The time lag in the liberation of reducing substances compared with the fall in viscosity suggests that two separate mechanisms may be involved. This possibility requires further study.

We have confirmed Favilli's observation, reported above, that diazotized compounds reduce the viscosity of mucin. We have encountered the same difficulties as he has in deciding whether $\mathrm{N}$-acetyl glucosamine or other reducing substances are liberated by these preparations. These difficulties arise from the coloured nature of the diazotized compounds and the difficulty of removing the soluble protein. Preliminary experiments to overcome these difficulties indicate that no reducing substances are liberated, but these observations require confirmation.

Robertson et al. ${ }^{10}$ state that the spontaneous loss of viscosity of vitreous humour is due to the activity of vitamin C. We have examined the diffusing and mucolytic activities of ascorbic acid in freshly boiled buffer at $p \mathrm{H} 7 \cdot 0$ and with the addition of one and two molecular equivalents of hydrogen peroxide. All three preparations cause a rapid fall in the viscosity of the substrate, the activity of the preparation with one equivalent of hydrogen peroxide being slightly greater than either of the others. No $\mathrm{N}$-acetyl glucosamine could be detected following the fall in viscosity. The increased diffusion in the dermis following the injection of these substances is marked, but it is of the same type as that caused by diazotized compounds; that is, the increase is not apparent in the first few minutes but develops during a period of three hours. The preparation with one equivalent of hydrogen peroxide spreads over a greater area than either of the others. Thus the mucolytic activity of ascorbic acid and its oxidation products is also associated with an increased diffusion in the dermis.

An explanation of the physiological function of the mucinase in testis extract and spermatozoa is provided by the observation of Kurzrok and Miller ${ }^{13}$ that semen contains a mucolytic enzyme whereby the spermatozoa are enabled to penetrate the plug of mucus normally present in the cervical canal of the uterus. The part played by bacterial mucinase in the metabolism of these organisms in artificial culture and on their invasive properties in the tissues is under investigation.

\footnotetext{
${ }^{1}$ Hoffmann and Duran-Reynals, J. Exp. Med., 53, 387 (1931); McClean, J. Path, and Bact., 33, 1045 (1930); 34, 459 (1931). 'Duran-Reynals, J. Exp. Med., 58, 161 (1933).

'McClean, J. Path, and Bact., 42, 477 (1936).

- Duran-Reynals and Stewart, Amer. J. Cancer, 15, 2790 (1931) ; Boyland and Meclean, $J$. Path. and Bact., 41, 553 (1935).

${ }^{5}$ Duran-Reynals, J. Exp. Med., 69, 69 (1939).

- Claude, J. Exp. Med., 66, 353 (1937).

'Morgan and McClean, J. Soc. Chem. Ind., 51, 44, 912 (1932); Claude and Duran-Reynals, J. Exp. Med., 65, 661 (1937); Madinaveitia, Biochem. J., 32, 1806 (1938); 33, 347 (1939) 33, 1470 (1939)

${ }^{8}$ Chain and Duthie, Nature, 144, 977 (1939).

Meyer, Hobby, Chaffee and Dawson J. Exp. Med., 71, 137 (1940).

1o Robertson, Ropes and Bauer, J. Biol. Chem., 133, 261 (1940).

11 Meyer and Palmer, J. Biol. Chem., 114, 689 (1936).

${ }^{12}$ Morgan and Elson, Biochem. J., 28, 988 (1934).

${ }^{13}$ Kurzrok and Miller, Amer. J. Obstet. and Gynoe., 1556 (1928); 24, 19 (1932).
}

\title{
APPLICATIONS OF ELECTRICITY IN IRON AND STEEL WORKS
}

\begin{abstract}
A REVIEW by H. G. Weaver of the progress made in the applications of electricity in iron and steel works during the last four years appears in the March issue of the Journal of the Institution of Electrical Engineers.

It appears to be now admitted that whereas WardLeonard control affords the most efficient method of providing the drive for the hoist and long-travel motions, the additional weight involved in the carry ing of the conversion set on the crab is considered to outweigh its advantages, and a plain direct-current series drive has proved the most popular, the motors being of the steel-clad mill pattern, with roller bearings and split frames.

The main point of interest with recent installations of drives for coal-handling plant is the universal adoption of totally enclosed, fan-cooled motors. The controls have a system of sequence interlocking,
\end{abstract}

which ensures that the stopping of certain conveyors will always automatically ensure the stopping of any other conveyors that are feeding them. More attention has recently been paid to the enclosure of the motors used in these plants, owing to the deleterious effect of the gases in the atmosphere. Special castings are used so far as possible, care being taken to see that they are free from porosity. Gas-proof gaskets and varnish are used for all frame and cover joints, and the windings carefully sealed with varnish and given extra coats of enamel.

In modern practice, the electrical equipment of blast furnace skip hoists is of the balanced type with two hoist motors on each. The weight of each basket empty is $12,000 \mathrm{lb}$, and the weight of each ore charge is $18,000-20,000 \mathrm{lb}$. The skip travel is $200 \mathrm{ft}$., at a speed of 450-600 ft./min. with an angle of incline of $53^{\circ}$ from the horizontal. Each hoist is driven by 
two 200 h.p., 220 volt, direct-current, steel-works type motors, with a speed range of 0 to 570-762 r.p.m., by shunt control, which are forced ventilated by motor-driven blowers, mounted on the top of the motor frame. The two motors are connected in series across a $310 \mathrm{kw}$., 440-volt generator. The two skip hoists are arranged by switching to run from any two of three motor-generator sets, each set comprising a 310 kw., 440-volt generator driven by a 450 h.p., 3-phase, slip-ring induction motor.

New features are continually being introduced in the electrical operation of the winch equipment for the charging bells of blast furnaces. In a recent example, the large bell is driven by a 17 h.p., D.c., compound wound motor, and the small bell by a 10 h.p. motor of the same type and speed. In each case the motor speed when raising the bell is 540 r.p.m., and when lowering the bell 840 r.p.m. The control is by contactors and resistances, and is so arranged that in the event of slack cable, the bell-lowering contactors are opened and the winoh is automatically reversed, so taking up the slack cable ; then after a short time interval the bell is automatically caused to lower again, and this operation is repeated until the bell falls away freely or the operation is tripped by hand. There is also complete interlocking of the bells so that one bell must have completed its full travel and also sealed before the other bell moves.

The production of iron in a modern blast furnace is a continuous process, and the main essential of furnace operation is therefore smooth and regular working, with as few stops as possible. The most difficult problem has been the development of a satisfactory method of stopping up the iron tapping hole when required without the necessity of shutting off the blast. An electrically driven clay gun has recently been introduced for this purpose. The gun itself is suspended from a boom, which swings it into position and holds it against the hole while plugging is taking place. The gun is driven by a $20 \mathrm{~h}$.p. motor and the boom by a 10 h.p. motor. They are switched direct on to the line without any overload or other type of protection, but limit switches are provided on both motions to prevent mechanical damage due to mal-operation of the controllers. The stalling torque of the 20 h.p. motor is $1 \cdot 6$ times full load torque and of the 10 h.p. $1 \cdot 35$ times full load torque, in each case when taking $2 \cdot 5$ times full load current at full line voltage. The boom motor is stalled when holding the gun against the hole. Very high ambient temperatures are encountered, and the motors have to be capable of withstanding stalling for half a minute under these conditions without excessive heating. They have 3 per cent nickel-steel shafts running in ball and roller bearings and are of welded steel construction throughout. The rotor windings consist of bronze bars secured in semienclosed slots, which are lined with anodized aluminium.

One plant for producing aluminium sheets has been equipped with a soaking pit furnace for ingots, a chain-conveyor furnace for slabs, cylindrical pitfurnaces for coil annealing and salt-bath furnaces for the heat treatment of sheets, all electrically heated and capable of dealing with aluminium. A particularly interesting development which is gaining ground more and more is the nitriding process, that is, the treatment of steel in an ammonia atmosphere, for the production of specially hardened parts.

\section{SEVENTY YEARS AGO}

\author{
NATURE, vol, 2, June 2, I870
}

Effects of Alcohol on the Human Body

A PAPER was read before the Royal Society on May 19 "On the Effects of Alcohol (Ethyl Alcohol) on the Human Body", by Dr. Parkes and Count Cyprian Wollowicz. The experiments were undertaken with a view of testing the physiological and especially the dietetic effects of alcohol. The subject was a healthy and very intelligent soldier of twentyeight, $5 \mathrm{ft} .6 \mathrm{in}$. in height, weighing 134-136 lb., with a clean, smooth skin, a clear bright eye, good teeth, largely developed powerful muscles, and but little fat. As he had been accustomed to smoke, he was allowed half an ounce of tobacco daily, lest the deprivation of it might disturb his health.

From the general results of the experiments, it appears that any quantity over $2 \mathrm{oz}$. of absolute alcohol would certainly do harm to this man, and that as every function was performed perfectly without it, its use was wholly unnecessary. Yet the experimenters recognize "the great practical benefit that may be derived from the use of alcohol in rousing a failing appetite, exciting a feeble heart, and accelerating a languid capillary circulation, though, for these objects to be fulfilled satisfactorily, there is necessity for great moderation and caution".

\section{Excessive and Depraved Appetite}

Perhaps the most extraordinary instance of excessive and depraved appetite on record is that of a French soldier, named Tarare, whose case is described in vol. XXI of the Dictionaire des Science Medicales. ... At 17 years of age, when only weighing $100 \mathrm{lb}$., he could eat $24 \mathrm{lb}$. of beef in as many hours. From the day of his admission to the army, he was ordered quadruple rations, with pickings and waste meat, but often slipped into the dispensary to finish off a poultice or two. One day he was observed to seize a large cat; and, after sucking its blood, left, in a very short time, only cleanly picked bones, the hair being rejected in the course of about half an hour. He was fond of serpents and eels, swallowing them whole. On another occasion he consumed in a few minutes a repast, spread out for fifteen German workpeople, of milk, etc., after which he was blown out like a balloon. . . . He fell under suspicion of having eaten a child fourteen months old.

\section{Whence come Meteorites?}

Prof. N. S. Maskelyne, F.R.S., has an article under this title in which he discusses views put forward by M. Stanislas Meunier, of the Jardin des Plantes, Paris. 'Whether M. Meunier's theoretical conclusions are to be looked on with the same favour that we heartily accord to his practical work is what we are about to discuss".

M. Meunier supposes meteorites to be the shattered morsels of a satellite smaller than and perhaps subordinated to the moon, which has run its course and been broken up by internal throes of volcano and earthquake. The fragments are thought to be "careering in every direction, retrograde as well as direct, around our world" and falling to the earth's surface in the order of their densities. Thus iron masses have already descended, stony fragments are now arriving, and the character even of these will change as time goes on. 